\title{
ARGUMENTAÇÃO, IMAGEM E DIREITO: UM ESTUDO DE CASO A PARTIR DA ANÁLISE DE PROVA EM VÍDEO ANEXADA A UM PROCESSO CRIMINAL MILITAR
}

ARGUMENTATION, IMAGE AND LAW: A CASE STUDY FROM THE ANALYSIS OF VIDEO EVIDENCE ATTACHED TO A MILITARY CRIMINAL CASE

\author{
ARGUMENTACIÓN, IMAGEN Y DERECHO: UN ESTUDIO DE CASO A PARTIR DEL \\ ANÁLISIS DE PRUEBA EN VIIDEO ANEXADO A UN PROCESO CRIMINAL MILITAR
}

\section{André Lázaro Ferreira Augusto'}

\section{Vicente Riccio²}

Licença CC BY:

Artigo distribuído sob os termos Creative Commons, permite uso e distribuição irrestrita em qualquer meio desde que o autor credite a fonte original.

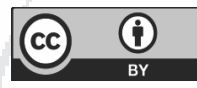

\begin{abstract}
Resumo: Este artigo analisa a argumentação de profissionais que atuaram em um processo criminal militar sobre uma prova audiovisual. A hipótese era a de que a argumentação não seria satisfatória, dadas as peculiaridades dessa prova e a ausência de um tratamento específico no Brasil. A partir da interface com a linguística textual, desenvolveu-se pesquisa de cunho empírico, qualitativo e descritivo, baseada no método do estudo de caso para a análise das marcas linguísticas e do direcionamento da força dos argumentos apresentados. Tal análise permitiu inferir a preferência na argumentação voltada ao vídeo, a discrepância entre a natureza demonstrativa na legitimação e substantiva na valoração dessa prova, a ausência de argumentação sobre os elementos multimodais e a incidência da teoria da testemunha silenciosa. A hipótese restou confirmada, concluindo-se pela necessidade de maior alfabetização digital dos profissionais do direito para lidar com a complexidade dessa espécie de prova.
\end{abstract}

1 Doutorando no curso de Linguística da Universidade Federal de Juiz de Fora, Minas Gerais, Brasil, é mestre em Direito pela mesma Universidade e graduado em Direito pela Universidade Federal Fluminense/RJ. Atuando como Juiz Federal da Justiça Militar desde 2009, integra grupo de pesquisa que estuda a prova em vídeo, em especial sua admissão e interpretação pelos profissionais que atuam em processos judiciais (e-mail: andre.lazaro@yahoo.com.br). Doutor em Sociologia pelo Instituto de Pesquisas do Estado do Rio de Janeiro (IUPERJ). Atualmente, é coordenador do programa de mestrado em Direito e Inovação da Universidade Federal de Juiz de Fora, Minas Gerais, Brasil. Seus interesses de pesquisa são: mídia e justiça, prova em vídeo, segurança pública, polícia e sociedade (e-mail: vicente.riccio@gmail.com)

3 Doutora em Letras/Estudos da Linguagem pela Pontifícia Universidade Católica do Rio de Janeiro (2007), é Professor Adjunto IV da Universidade Federal de Juiz de Fora, Minas Gerais, Brasil, atuando como professora na Faculdade de Letras e na Pós-Graduação em Linguística. Desenvolve pesquisas na área da Sociolinguística Interacional e na interface gramática e interação, com ênfase em argumentação e avaliação em dois contextos institucionais: PROCON e Audiências do Juizado Especial Criminal (e-mail: amitzatv@yahoo.com.br). 
Resumo: Este artigo analisa a argumentação de profissionais que atuaram em um processo criminal militar sobre uma prova audiovisual. A hipótese era a de que a argumentação não seria satisfatória, dadas as peculiaridades dessa prova e a ausência de um tratamento específico no Brasil. A partir da interface com a linguística textual, desenvolveu-se pesquisa de cunho empírico, qualitativo e descritivo, baseada no método do estudo de caso para a análise das marcas linguísticas e do direcionamento da força dos argumentos apresentados. Tal análise permitiu inferir a preferência na argumentação voltada ao vídeo, a discrepância entre a natureza demonstrativa na legitimação e substantiva na valoração dessa prova, a ausência de argumentação sobre os elementos multimodais e a incidência da teoria da testemunha silenciosa. A hipótese restou confirmada, concluindo-se pela necessidade de maior alfabetização digital dos profissionais do direito para lidar com a complexidade dessa espécie de prova.

Palavras-Chave: Imagem; Direito; Prova em vídeo; Alfabetização visual; Análise linguística.

Abstract: This article analyzes the arguments of professionals who worked in a military criminal proceeding with audiovisual evidence. The hypothesis was that the argument would not be satisfactory, given the peculiarities of this evidence and the absence of specific treatment in Brazil. Based on the interface with textual linguistics, an empirical, qualitative and descriptive study was conducted, using the case study method to analyze the linguistic markers and the thrust of the arguments presented. This analysis enabled us to infer a preference for arguments focusing on the video evidence, a discrepancy between the demonstrative nature in the legitimation and substantive in the valuation of this evidence, the absence of argumentation about the multimodal elements, and the incidence of the theory of silent witness. The hypothesis was confirmed, concluding with the need for greater digital literacy for legal professionals, to enable them to deal with the complexity of this kind of evidence.

Keywords: Image; Law; Video Evidence; Visual Literacy; Linguistic Analysis.

Resumen: Este artículo analiza la argumentación de profesionales que actuaron en un proceso criminal militar sobre una prueba audiovisual. La hipótesis era la de que la argumentación no sería satisfactoria, dadas las peculiaridades de esa prueba y la ausencia de un tratamiento específico en Brasil. A partir de la interfaz con la linguística textual, se desarrolló una investigación de cuño empírico, cualitativo y descriptivo, basada en el método de estudio de caso para el análisis de las marcas linguísticas y de dirección de la fuerza de los argumentos presentados. Tal análisis permitió deducir la preferencia en la argumentación direccionada al vídeo, la discrepancia entre la naturaleza demostrativa en la legitimación y substantiva en la valoración de esa prueba, la ausencia de argumentación sobre los elementos multimodales y la incidencia de la teoría del testigo silencioso. La hipótesis restó confirmada, concluyéndose por la necesidad de mayor alfabetización digital de los profesionales del derecho para lidar con la complejidad de esta especie de prueba.

Palabras clave: Imagen; Derecho; Prueba en vídeo; Alfabetización visual; Análisis linguística.

\section{INTRODUÇÃO}

A sociedade contemporânea é marcada pelo uso da mídia, em especial da audiovisual. Os meios de comunicação, a disseminação da mídia audiovisual e os avanços tecnológicos recentes definiram um novo modo de interação e conhecimento da realidade. Atualmente, as experiências 
vivenciadas pelas pessoas não mais se restringem em tempo e espaço. Fatos ocorridos a milhares de quilômetros de distância participam do cotidiano e são debatidos, contestados e julgados por um número indeterminado de pessoas.

A mídia audiovisual está presente em diversas situações, como no consumo de produtos culturais, em notícias televisivas, em comunidades nas redes sociais e na disseminação de informações produzidas por smartphones por testemunhas de um evento específico. Essa pluralidade de situações afeta, também, o campo do direito. O jornalismo audiovisual, por exemplo, aborda diversos temas jurídicos. Mas, a incidência da mídia audiovisual não se limita a conferir maior publicidade ao direito: ela, igualmente, passou a se incorporar ao trabalho dos profissionais dessa área, dada a crescente presença de registros audiovisuais nos processos em trâmite nas cortes dos mais diversos países.

O campo de estudos sobre direito e mídia é vasto e comporta objetos e metodologias distintas. Este artigo tem como interesse de estudo a utilização da imagem audiovisual no processo de deliberação judicial, marcado por sua natureza argumentativa. A presente pesquisa, de cunho empírico, qualitativo e descritivo, adotou o método do estudo de caso para investigar como os profissionais que atuaram em um determinado processo julgado pela Justiça Militar da União argumentaram sobre as provas produzidas, em especial o registro audiovisual da cena do crime.

Tem-se como hipótese que a argumentação não será satisfatória, dadas as peculiaridades da prova em registro audiovisual e a ausência de um tratamento específico no Brasil para essa modalidade de prova. A legislação, a doutrina e o ensino do direito são voltados ao exame das provas orais (depoimentos de testemunhas, de peritos e das partes) e das provas escritas (documentos, como os contratos). Quando há a inserção de uma prova em vídeo em um processo, os profissionais que nele atuam adaptam as normas e o conhecimento jurídico voltado às provas escritas para poderem laborar com essa espécie de evidência. Tal analogia não geraria resultados satisfatórios, dadas as diferenças observáveis entre um texto escrito e uma filmagem. Ademais, não só a presença de elementos multimodais (imagens, sons, foco, enquadramento, perspectiva da câmera, movimentos, iluminação, dentre outros) tornam a prova em registro audiovisual singular: a ausência de treinamento impede aos seus intérpretes a consciência da falta de objetividade do presente no vídeo, devido à miríade de interpretações possíveis e aos sentimentos evocados no ato de assistir às filmagens.

Para a avaliação da qualidade da argumentação, buscou-se a perspectiva multidisciplinar, compreendida como a interação entre ciências para a solução de um problema. A partir da interface com a Linguística, em sua concepção textual, foram analisadas as marcas linguísticas do enunciado e o direcionamento da força argumentativa. Tal análise permitiu a verificação do modo como foi valorada a prova em vídeo. Além disso, o estudo verificou a maneira com que os profissionais compreenderam a natureza da prova incorporada ao processo, demonstrativa ou substantiva, e os argumentos utilizados para sustentar suas posições. Por fim, o artigo discute a capacidade dos profissionais do direito em analisar o conteúdo audiovisual trazido ao processo como meio de prova. 
Como observado anteriormente, a sociedade contemporânea é caracterizada pelo uso da mídia, em especial da audiovisual. Essa presença não é tímida. Ao contrário, é ubíqua e excessiva. A todo instante, múltiplos estímulos visuais circundam as pessoas e a adaptação a essa realidade é desafiadora. Richard Sherwin define essa situação como o barroco digital, em que há uma profusão de imagens sobrepostas de difícil interpretação, tal qual se observava nas pinturas excessivamente detalhistas desse estilo artístico. A maneira como o raciocínio jurídico é estabelecido, tendo em vista fatores como experiência de vida, capital cultural, origem socioeconômica, dentre outros, interfere nas percepções dos indivíduos acerca dos fatos. A "alfabetização visual significa conhecer como as imagens criam certas impressões e como elas constroem ou evocam significados visuais pré-concebidos"4. Assim, é uma ferramenta que pode fornecer os elementos para a adequada compreensão do papel da imagem por parte do operador do direito, munindo-o de mecanismos para a neutralização de vieses que podem influenciar o que seus olhos veem.

Ela é importante especialmente em razão da tendência observada por Silbey ${ }^{5}$ em reafirmar certos mitos sobre a imagem, especialmente nas cortes. Eles seriam a crença na objetividade dos vídeos, a inexistência de ambiguidade e a transformação em testemunha presencial daquele que assiste à imagem registrada em vídeo. Essa crença na objetividade da imagem gerou a teoria da testemunha silenciosa ${ }^{6}$. O pressuposto básico era deixar a câmera falar por si mesma e o espectador testemunhar com seus próprios olhos o fato.

A expansão das câmeras de monitoramento e vigilância em espaços públicos e privados, bem como o desenvolvimento de smartphones, ampliou a oferta de imagens para apreciação judicial. A perspectiva crítica em relação à imagem deve ser considerada, pois no processo de convencimento do juiz estão os elementos próprios do direito e das ciências físicas que se encontram ao longo do processo ${ }^{7}$. Ademais, a prova em vídeo coloca em evidência o papel do perito, pois sua competência técnica pode validar ou não o conteúdo apresentado ${ }^{8}$.

O fenômeno da testemunha silenciosa pôde ser observado em um caso de grande repercussão nos Estados Unidos julgado por sua Suprema Corte: Scott v. Harris. O caso trata de uma perseguição policial na qual o policial Scott joga seu carro de patrulha contra o veículo do fugitivo Harris. Ele

$4 \quad$ SHERWIN, Richard K. Visualizing law in the age of the digital baroque: arabesques and entanglements, $p$. 40.TAIT, David. Rethinking the role of the image in justice: visual evidence and science in the trial process. Law, Probability and Risk, 6, 2007, p. 313.

5 SILBEY, Jessica. Race, Religion, Gender \& Class, p. 104.

6 GARDNER, Dillard S. The Camera goes to court. North Carolina Law Review, Chapel Hill, v. 24, n. 3, 1946, p. 245.

7 FELICE, Deborah, SAGRI, Teresa, BACCI, Lorenzo, AGNOLONI, Tommaso. I "Nuovi" strumenti di conoscenza nella costruzione del giudizio penale: un'analisi tra sociologia del diritto e informatica giuridica. In: GHEZZI, Morris; MOSCONI, Giuseppe; PENNISI,Carlo; PRINA; RAITERI, Monica (coor.). Processo Penale, Cultura Giuridica e Ricerca Empirica, Santarcangelo di Romagna: Maggioli, 2017, p. 56).

8 FELICE, Deborah. II Sapere Specialistico nel Giudizio Penale: profili d'analisi di sociologia del diritto. Milano: Mimesis, 2014, p. 73. 
consegue retirar o suspeito da estrada, que ficou tetraplégico com o acidente. Inconformado, o suspeito ajuizou ação indenizatória contra o policial por uso excessivo da força. O policial usou em sua defesa o vídeo da perseguição, captado por uma câmera acoplada à viatura, para comprovar o uso proporcional dos meios à disposição. Após intenso debate por parte dos juízes da Suprema Corte sobre as imagens, os argumentos do policial foram acolhidos por 8 votos contra 1.

O ponto importante nessa decisão é o modo como o vídeo foi interpretado. As análises posteriores da decisão da Corte Suprema apontam uma excessiva confiança dos juízes nas imagens registradas em vídeo. Ele foi aceito como relato fidedigno do ocorrido, embora suas nuances não tenham sido abordadas por ocasião do julgamento. Em seu voto, o juiz Anthony Scalia se declara

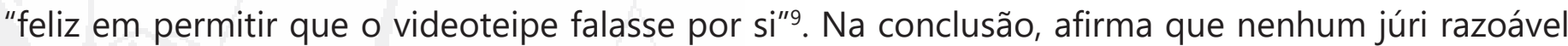
interpretaria as imagens apontando o uso desproporcional da força. Afirmou, ainda, que era a perseguição policial mais excitante desde Operação França ${ }^{10}$. O único voto divergente interpretou o vídeo de modo distinto e questionou o suposto perigo criado à coletividade pelo suspeito ao dirigir em alta velocidade em uma via deserta. O voto vencido do juiz Stevens baseou-se em nova interpretação das imagens e na apreciação de outros detalhes não observados pelos demais integrantes da Corte ${ }^{11}$.

A partir do caso Scott v. Harris, Kahan ${ }^{12}$ estudou quatro grupos representativos da sociedade americana para verificar quais seriam as suas percepções sobre o vídeo da perseguição policial. Baseando-se nas teorias do modelo de controle de culpa, da cognição da proteção da identidade e da cognição cultural do risco, formulou a hipótese de que pessoas com identidades e compromissos diversos formam concepções diversas sobre fatos apresentados em vídeo. O resultado de sua pesquisa demonstrou que indivíduos, particularmente homens, brancos, ricos e ligados a visões culturais hierárquicas e individualistas, adotaram o mesmo posicionamento firmado pelo voto vencedor da Suprema Corte. No entanto, para um subgrupo formado por afro-americanos, mulheres, pobres e com valores igualitários, o posicionamento foi o contrário.

Essa validação instantânea da imagem é questionada por Sherwin ${ }^{13}$, pois ver não significaria crer, apesar de as imagens parecerem representar a realidade como ela é. A imagem precisa ser escrutinada com rigor para evitar excessos e pontos de vista distorcidos. Esse aspecto é relevante dado o risco da incorporação da imagem no contexto probatório do processo reafirmando seus mitos, quais sejam: 1 - imagens de vídeo são objetivas, 2 - seus significados são óbvios e desprovidos de ambiguidades, e 3 - o filme transforma o observador em testemunha ${ }^{14}$. A grande

$9 \quad$ ESTADOS UNIDOS DA AMÉRICA. Suprema Corte. 550 U.S. 372. Scott v Harris. Relator Juiz Antonin Gregory Scalia. Washington, 30 de abril de 2007, p. 378.

10 Filme americano de 1971 dirigido por John Frankenheimer que mostra dois detetives de Nova lorque investigando uma rede de tráfico de heroína originada na França. O filme ficou famoso, principalmente, pelas perseguições de carros nas ruas de Marseille. Disponível em https://www.imdb.com/title/tt0067116/ em 16/04/19.

11 YOWELL, Amelia G. Race to judgment? An empirical study of Scott v. Harris and summary judgment. Notre Dame Law Review, Notre Dame, v. 85, n 4, 2010, p. 1768.

12 KAHAN, Dan M. Harvard Law Review, p. 850.

13 SHERWIN, Richard K. Visualizing law in the age of the digital baroque: arabesques and entanglements, $p$. 43.

14 SILBEY, Jessica. Race, Religion, Gender \& Class, p. 104 
crítica em relação ao caso Scott vs. Harris reside na reafirmação dos mitos da imagem por parte dos julgadores. Sherwin ${ }^{15}$ reforça esse ponto ao citar estudos que analisaram a apropriação do elemento visual no âmbito da instrução probatória e em seu processo de argumentação jurídica. A comparação entre a resposta a estímulos visuais e escritos no âmbito de processos judiciais conduz a associações distintas. Os estímulos baseados em vídeo levariam a associações psicológicas e mentais inconscientes relacionadas a elementos como a memória, a experiência e a fantasia. Tais elementos se agregariam ao processamento mental da imagem de modo muito rápido, impedindo a atuação de filtros racionais responsáveis por uma reflexão mais crítica em relação ao observado. O efeito disso é enxergar o esperado, o subjetivamente desejado. Logo, é impossível o filme falar por si mesmo, pois ele não apresenta uma interpretação pronta e definida. A compreensão dos contornos explícitos e implícitos da imagem é de fundamental importância para a sua correta apropriação, especialmente no contexto judicial. A alfabetização visual promoveria a competência adequada para a compreensão da imagem por parte do profissional do direito.

Silbey $^{16}$ retoma essa questão ao criticar a teoria da testemunha silenciosa e menciona ser testemunha ilusória, porque o potencial persuasivo das imagens desperta nos espectadores julgamentos baseados na emoção. A alfabetização visual é a capacidade do profissional do direito em mobilizar os diversos recursos cognitivos para corroborar ou enfraquecer uma versão aparentemente dominante do argumento apresentado pelo vídeo. Assim, o vídeo é mais um elemento a ser submetido ao cross-examination como outros tipos de elementos probatórios.

A fim de investigar a intensidade da argumentação das partes acerca da prova em vídeo, Silbey ${ }^{17}$ desenvolveu pesquisa analisando alguns casos submetidos às Cortes Americanas para avaliar se a interpretação da natureza da evidência (demonstrativa ou substantiva) correspondia aos procedimentos adotados e à valoração conferida. A evidência substantiva é o meio de prova diretamente relacionado ao fato em disputa. A sua validade não depende de outro elemento, pois é suficiente para sustentar um ponto de vista. Desse modo, a sua admissibilidade no direito norteamericano é definida em razão de sua relevância e legitimidade.

A evidência demonstrativa, por seu turno, é criada para ilustrar argumentos, como os fluxogramas, os diagramas e os modelos, ou explicitar uma outra prova, quando utilizada para o esclarecimento do depoimento de uma testemunha, por exemplo. Logo, a evidência demonstrativa não é autossuficiente; ela depende de outro elemento para a sua validação. Um diagrama não basta para provar um fato. Sua utilização em juízo vem no auxílio de outra evidência substantiva, como o depoimento de uma testemunha ou um conjunto de documentos, dentre outros. Em síntese, a evidência demonstrativa serve para corroborar, explicar, uma evidência substantiva.

15 SHERWIN, Richard K. Visualizing law in the age of the digital baroque: arabesques and entanglements, $p$. 2.

16 SILBEY, Jessica. Race, Religion, Gender \& Class, p. 110-112.

17 SILBEY, Jessica. Judge as film critics: new approaches to filmic evidence. University of Michigan Journal of Law Reform, Ann Arbor, vol. 37, n. 2., 2004, p. 498-499. 
A pesquisa de Silbey ${ }^{18}$ analisou como o vídeo era admitido nas cortes, se no formato substantivo ou demonstrativo. Dos 7 casos analisados, em $71 \%$ os vídeos foram admitidos como prova demonstrativa, embora posteriormente sua valoração fora como prova substantiva.

No Direito Processual Penal Brasileiro inexistem regras específicas para o tratamento da prova em vídeo. A doutrina processual penal, de modo a buscar uma solução, tem adotado conceitos mais amplos de documento ${ }^{19}$, de modo que as filmagens possam ser compreendidas nessa modalidade probatória. Como exemplos podem ser citados "qualquer objeto móvel que dentro do processo possa ser utilizado como prova"20, ou "qualquer objeto representativo de um fato ou ato relevante"21. Com isso, são aplicadas as mesmas normas referentes à prova documental.

Ademais, não há a previsão de uma fase inicial na instrução dos feitos voltada à deliberação da admissão da prova em vídeo. Normalmente, não se discutem referências ao modo como a prova foi obtida ou qual a sua natureza (demonstrativa ou substantiva) e o seu impacto na persuasão racional do julgador. A adoção desses critérios, presentes no direito norte-americano, tornariam a análise das imagens por parte dos profissionais do direito brasileiros mais adequada.

\section{A LINGUÍSTICA TEXTUAL E O ESTUDO DA ARGUMENTAÇÃO DAS PARTES SOBRE O VÍDEO}

A Linguística Textual se desenvolveu a partir do estudo dos mecanismos interfrásticos do sistema gramatical da língua, de modo que sequências ordenadas pudessem ser reconhecidas como um texto. Uma de suas primeiras preocupações foi a de construir gramáticas textuais, responsáveis por descrever categorias de palavras e regras de combinação de um texto em determinada língua. A perspectiva inicial aos poucos englobou uma orientação semântica, voltada ao significado e ao processo de interpretação do texto e de seus componentes. No entanto, mantinha-se o estudo da língua como um fenômeno autônomo. A orientação pragmática passou a defender a análise do texto baseada em sua relação com os processos comunicativos de uma sociedade concreta, revelando uma orientação externa na busca da significação. À orientação externa, seguiu-se uma de caráter interno, cognitivista, ocupada em analisar os modelos mentais de operações e seus tipos de operações. Da união dessas duas últimas vertentes surgiu a perspectiva sociocognitivo-interacionista. Nessa abordagem, os sujeitos são vistos como atores/construtores sociais e o texto como o lugar próprio da interação específica, com um fim argumentativo próprio ${ }^{22}$.

18 SILBEY, Jessica. University of Michigan Journal of Law Reform, pp. 493-571.

19 O conceito estrito abrangeria apenas os escritos, públicos e particulares, conforme preveem o artigo 232 do CPP e o artigo 371 do CPPM.

20 LOPES JÚNIOR, Aury. Direito processual penal e sua conformidade constitucional, v. 1.5 ed. Rio de Janeiro: Lumen Juris, 2011, p. 685.

21 LIMA, Renato Brasileiro de. Manual de processo penal. v.1. Niterói: Impetus, 2011, p. 1025.

$22 \mathrm{KOCH}$, Ingedore Grunfeld Villaça. Introdução à linguística textual: trajetória e grandes temas, p. 19-44. 
A direção para a qual aponta a argumentação é verificável mediante a análise dos elementos textuais escolhidos pelos interagentes. Esses elementos constituem as marcas linguísticas do enunciado $^{23}$ e podem consistir em operadores argumentativos, marcadores de pressuposição, indicadores modais, índices de avaliação e casos de polifonia ${ }^{24}$, cujas funções são sintetizadas na tabela seguinte e explicadas nos próximos parágrafos.

Tabela 1 - Recursos argumentativos ${ }^{25}$ :

\begin{tabular}{|l|l|}
\hline \multirow{4}{*}{$\begin{array}{c}\text { Operadores } \\
\text { Argumentativos }\end{array}$} & $\begin{array}{l}\text { Indicam o argumento mais forte de uma escala orientada no sentido de uma } \\
\text { conclusão. }\end{array}$ \\
\cline { 2 - 2 } & Somam argumentos orientados a uma mesma conclusão ou a um mesmo sentido \\
\cline { 2 - 2 } & Introduzem uma conclusão relativa a argumentos em enunciados anteriores \\
\cline { 2 - 2 } & Introduzem argumentos alternativos que levam a conclusões diferentes ou opostas \\
\cline { 2 - 3 } & Estabelecem relação de comparação entre elementos, orientada a uma conclusão \\
\cline { 2 - 3 } & Introduzem uma causa, justificativa ou explicação relativa ao enunciado anterior \\
\hline & Contrapõem argumentos orientados para conclusões contrárias \\
\hline & Introduzem no enunciado conteúdos pressupostos \\
\hline & Introduzem argumento para esclarecer um enunciado anterior, ajustando seu sentido \\
\hline & Introduzem uma comprovação, embora não relacione o conteúdo de proposiçães \\
\hline
\end{tabular}

Marcadores de pressuposição

Conectores circunstanciais que introduzem uma oração anteposta

Indicadores modais Epistêmicos

Deônticos

Índices de avaliação

Indicadores atitudinais

Indicadores de domínio

Indicadores de subjetividade

Operadores argumentativos de negação, contrariedade e conclusivos Ironia e discurso indireto livre

Polifonia Argumento de autoridade

Verbos que marcam pressuposição ou metáfora temporal

23 Enunciado é "a manifestação concreta de uma frase, em situação de interlocução" (KOCH, Ingedore Grunfeld Villaça. Introdução à linguística textual: trajetória e grandes temas, p. 11).

$24 \mathrm{KOCH}$, Ingedore Grunfeld Villaça. Argumentação e Linguagem, p. 102-105, 128, 141-144; KOCH, Ingedore Grunfeld Villaça. A inter-ação pela linguagem, p. 31-39, 46-53, 64-65.

$25 \mathrm{KOCH}$, Ingedore Grunfeld Villaça. A intertextualidade como critério de textualidade, p. 228-234. $\mathrm{KOCH}$, Ingedore Grunfeld Villaça. Argumentação e Linguagem, p. 102-105, 128, 141-144. KOCH, Ingedore Grunfeld Villaça. A inter-ação pela linguagem, p.31-39, 42-53, 64-65. THOMPSON, Geoff; HUNSTON, Susan. Evaluation in Text: Authorial Stance and the Construction of Discourse, p. 21. 
Os operadore argumentativos são nomes ou expressões que, em uma dada classe argumentativa ${ }^{26}$, indicam a escala argumentativa ${ }^{27}$ . Uma escala argumentativa pode ser representada graficamente, conforme o exemplo:

Ele jantou

Argumento mais forte da escala

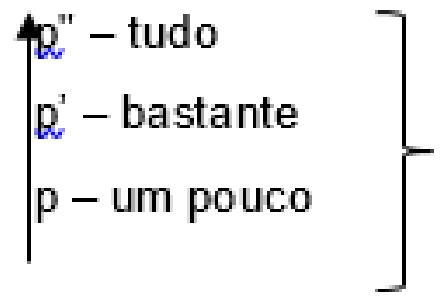

ontem.

\section{Mesma classe}

argumentativa

Na lacuna presente no enunciado ele jantou ontem podem ser inseridos operadores com variadas intensidades de argumentação, desde um pouco, indicando a menor delas, até tudo, representando o seu grau mais forte. Assim, uma escala argumentativa pode conter diversos tipos de operadores argumentativos, responsáveis por descrever o desenvolvimento e a intensidade da argumentação.

Os marcadores de pressuposição introduzem conteúdos semânticos pressupostos. No enunciado João passou a faltar ao trabalho, o enunciador pressupõe o fato de João ser um trabalhador assíduo. De acordo com Koch, são constituídos pelos verbos indicativos de mudança ou permanência de estado (ficar, permanecer, continuar etc.), verbos factivos (indicam um estado psicológico, como lamentar, sentir, saber etc.) e pela retórica da pressuposição, caracterizada pela apresentação de uma informação vinculada à outra informação subsequente. Um exemplo de uso da retórica da pressuposição é a informação "lamentamos o inconveniente", por vezes observada em estabelecimentos comerciais em obras. O último termo (inconveniente, pertinente a transtornos ocasionáveis pela obra) é tido como pressuposto, apesar de consistir na informação principal (o alerta para a existência da obra em si).

Indicadores modais demonstram o modo como algo é dito, pois um mesmo enunciado pode ser influenciado por diversas modalidades. Derivados de estudos da lógica clássica, a divisão compreende os enunciados aléticos (indicando necessidade ou possibilidade), epistêmicos (certeza ou dúvida) e deônticos (obrigatoriedade ou facultatividade). Geralmente têm como característica o emprego dos verbos auxiliares dever ou poder, como se observa nos enunciados apresentados por Koch: "deve estar nevando em Paris" (alético, indicando possibilidade), "você deve cumprir seus deveres para com a firma" (deôntico, indicando obrigatoriedade) e "os inimigos devem ser uns cem" (epistêmico, indicando dúvida).

26 "Classe argumentativa é constituída de um conjunto de enunciados que podem servir de argumento para uma mesma conclusão" (KOCH, Ingedore Grunfeld Villaça. A inter-ação pela linguagem, p. 30).

27 Escala argumentativa é a gradação de força de dois ou mais enunciados de uma mesma classe argumentativa $(\mathrm{KOCH}$, Ingedore Grunfeld Villaça. A inter-ação pela linguagem, p. 11). 
Nos índices de avaliação, o responsável pela argumentação avalia um fato, o seu contexto ou o sentimento que nutre por ele. O primeiro deles é representado pelos marcadores de subjetividade e incluem nomes empregados a partir da carga valorativa a respeito de um ato ou fato. Um exemplo é o enunciado "ele implorou por perdão". O ato é de grande intensidade se comparado ao enunciado "ele pediu perdão".

Os índices de domínio são compostos pelo contexto de entendimento de um fato (estrategicamente, economicamente) ou pelo modo de sua formulação (secretamente, abertamente, resumidamente). Os indicadores atitudinais são nomes e expressões que apresentam o estado psicológico do enunciador acerca do fato (alegremente, infelizmente).

A polifonia é o fenômeno caracterizado pela presença de uma fala de perspectiva diversa, podendo ou não ter a concordância do enunciador. As formas mais comuns são o emprego de provérbios ou ditos populares (água mole em pedra dura tanto bate até que fura) e no argumento de autoridade (segundo a bíblia, a preguiça é um dos pecados capitais).

Todo esse ferramental disponível na linguística textual permite salientar as nuances da forma e da força argumentativa empregadas. Por tais razões, foi estabelecida com ela uma interface para, na presente pesquisa, serem evidenciadas eventuais distinções entre a forma de argumentar sobre a prova em vídeo e sobre as demais provas carreadas ao feito. Igualmente auxiliou na observação da natureza do vídeo adotada pelos profissionais no processo e sua respectiva valoração (como evidência demonstrativa ou substantiva).

\section{METODOLOGIA E CONTEXTO DO ESTUDO}

\subsection{CARACTERIZAÇÃO DA PESQUISA E DO MÉTODO ADOTADOS}

Pesquisa é o procedimento orientado a responder questões propostas ${ }^{28}$. As questões podem ter fundo puramente teórico, como o choque entre teorias já existentes, ou a perspectiva empírica, voltada à observação de um fenômeno existente no mundo real e suas influências na sociedade. Como o objetivo não era simplesmente revisitar teorias para a realização de uma crítica e a sugestão de uma nova teoria (tipo de pesquisa que impera no direito) e sim o de observar um fenômeno real (a argumentação sobre uma prova em vídeo) e seus impactos (informações relativas a capacidade de os profissionais trabalharem com essa espécie de evidência e seus reflexos nas decisões judiciais), esta pesquisa foi direcionada a um problema empírico.

A análise dos dados empíricos poderá ser quantitativa ou qualitativa. $\mathrm{Na}$ análise qualitativa se almeja a compreensão do objeto em toda a sua complexidade, o que importa na sua observação no contexto em que ocorre. Para tanto, desde a etapa da coleta de dados, cabe uma postura mais

28 GIL, Antonio C. Como elaborar projetos de pesquisa. 4 ed. São Paulo: Atlas, 2002, p. 17. 
abertura do pesquisador, de modo que teorias e hipóteses até então construídas não limitem sua atuação. Isso pode implicar, inclusive, na adaptação de métodos e técnicas às peculiaridades da pesquisa que está desenvolvendo ${ }^{29}$. A análise quantitativa, por outro lado, analisa o fenômeno isolando algumas de suas variáveis, a partir de procedimentos realizados em laboratório ou em condições que afastem interferências externas, inclusive na fase de análise de dados. Essa postura visa a obtenção de maior objetividade e generalidade das respostas, o que poderia ser frustrado pela subjetividade do pesquisador ${ }^{30}$. Considerando que o cerne da atual pesquisa é a interação entre pessoas naturais em um contexto profissional, no qual são relevantes suas opiniões e intenções para a verificação dos argumentos utilizados sobre a evidência em registro audiovisual, revela-se adequada e pertinente à pesquisa a análise qualitativa, temperada com algumas observações de cunho quantitativo.

Com relação aos seus objetivos gerais, as pesquisas podem ser classificadas em exploratórias, explicativas e descritivas: as exploratórias permitem maior aproximação com um determinado fenômeno com vistas a construção de hipóteses; as explicativas possibilitam a identificação dos fatores que determinam ou contribuem para a gênese de um dado fenômeno; e nas descritivas são observadas as características do fenômeno em estudo para o estabelecimento de relações entre

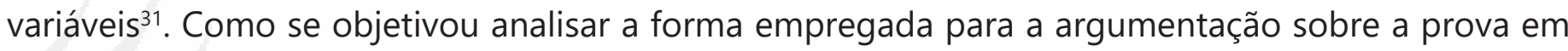
vídeo, sua relação com a admissão e valoração dessa evidência e a aptidão dos profissionais nessas tarefas, adotou-se a pesquisa de cunho descritiva.

Há diversos métodos que podem ser escolhidos para conduzir uma pesquisa, dentre eles o experimento, o levantamento, a análise de arquivos, a pesquisa histórica e o estudo de caso. Entretanto, os métodos não podem ser aleatoriamente escolhidos, sob pena de frustrar o alcance dos resultados esperados. Para Yin ${ }^{32}$, à escolha se devem analisar três elementos: o problema de pesquisa em si, a forma como será exercido o controle pelo pesquisador dos comportamentos a serem observados e se esses comportamentos são contemporâneos ou não.

O problema de pesquisa é formulado mediante uma pergunta utilizando-se advérbios interrogativos (quem, como, por que, qual). Na presente, a pergunta norteadora é "como se desenvolve a argumentação sobre a prova em vídeo em um processo criminal militar?". Indagações com o advérbio "como" tendem a pesquisas descritivas e que estão ligadas aos métodos do experimento, da pesquisa histórica e do estudo de caso. Na pesquisa desenvolvida a exigência do controle de eventos comportamentais não esteve presente, pois a fonte dos dados foi um caso concreto arquivado. Apenas a pesquisa histórica e o estudo de caso não necessitam desse controle por lidarem com um "passado morto", sem o acesso direto ao evento. O último dos elementos é a contemporaneidade: dentre as opções remanescentes apenas o estudo de caso permite ao pesquisador o acesso a uma maior variedade de evidências, que podem ser coletadas mediante técnicas como a entrevista dos

29 GIL, Antonio C. Como elaborar projetos de pesquisa. 4 ed. São Paulo: Atlas, 2002, p. 202.

30 GUNTHER, Hartmut. Pesquisa Qualitativa Versus Pesquisa Quantitativa: Está É a Questão? in Psicologia: Teoria e Pesquisa, v. 22, n. 2. Brasília: Universidade de Brasília, mai/ago de 2006. Disponível em: <http://dx.doi. org/10.1590/S0102-37722006000200010>. Acesso em 25/09/2017.

31 GIL, Antonio C. Como elaborar projetos de pesquisa. 4 ed. São Paulo: Atlas, 2002, p. 41 a 43.

32 YIN, Robert K. Estudo de caso: planejamento e métodos. 5 ed. Porto Alegre: Bookman, 2015, p. 9. 


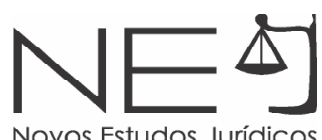

participantes do evento. Apesar de no momento da realização da presente pesquisa não estar prevista a utilização de mecanismos que pudessem superar as possibilidades da pesquisa histórica, optou-se pela adoção do método do estudo de caso para a facilitação de eventuais desdobramentos futuros do trabalho, em que poderá ser adotado o enfoque explicativo mediante o exame de evidências contemporâneas ${ }^{33}$.

O estudo de caso tem por objetivo investigar "um fenômeno contemporâneo ('o caso') em profundidade e em seu contexto de mundo real, especialmente quando os limites entre o fenômeno e o contexto puderem não ser claramente evidentes" ${ }^{\prime \prime 4}$. Compreende diversas etapas: a revisão de teorias que oferecerão o suporte para a investigação a ser realizada, inclusive com subsídios para a construção de problemas de pesquisa ou hipóteses (tópicos 2 e 3); a coleta de dados a partir de um protocolo orientado à criação de um banco de dados com todas as evidências disponíveis; e a análise dos dados (tópico 4) com a elaboração de um relatório da pesquisa ${ }^{35}$.

\subsection{O CONTEXTO DO CASO}

O presente estudo analisa um processo criminal militar tramitado na Justiça Militar da União contendo um vídeo registrado por um telefone celular. Um oficial do Exército Brasileiro observou um soldado assistindo a um vídeo de uma situação ocorrida em um alojamento do quartel. No vídeo, um cabo aplicava um golpe de jiu-jitsu em um soldado, que urrava pedindo para ser libertado. Durante essa interação, um segundo soldado adentrou à cena e passou a sufocar a vítima com uma toalha, momento em que os gritos aumentam de intensidade. Ao final, o soldado é liberado pelos agentes, senta-se em um banco do vestiário e troca de roupa para sair. O vídeo serviu tanto para a instauração do inquérito policial militar como prova de um processo que resultou em condenação na $1^{a}$ instância. Após a sentença, houve recurso ao Superior Tribunal Militar, mantendo a sentença anteriormente prolatada.

A pesquisa analisou os argumentos utilizados no processo pelo Promotor de Justiça Militar, pelo Defensor Público Federal, pela Juíza-Auditora e pelo Ministro no Superior Tribunal Militar ${ }^{36}$, os últimos sendo os relatores das decisões de primeira e segunda instância.

\section{ANÁLISE DE DADOS}

O trabalho de pesquisa teve início com a análise de todos os documentos do processo que apresentavam algum tipo de argumentação sobre as provas, compreendendo a denúncia, as alegações escritas das partes, a sentença, a ata do julgamento, as razões e contrarrarazões recursais e o voto do Ministro Relator no julgamento da apelação. Separados esses documentos, foram

33 YIN, Robert K. Estudo de caso: planejamento e métodos. 5 ed. Porto Alegre: Bookman, 2015, p. 22, 44.

34 YIN, Robert K. Estudo de caso: planejamento e métodos. 5 ed. Porto Alegre: Bookman, 2015. p. 17.

35 YIN, Robert K. Pesquisa qualitativa do início ao fim. Porto Alegre: Penso, 2016.

$36 \mathrm{Na}$ justiça militar brasileira as decisões são tomadas um colegiado composto por um juiz formado em direito e quatro juízes militares na primeira e segunda instância. 
separadas em excertos todas as ocorrências de argumentos sobre a prova em vídeo, sobre as demais provas (restringiram-se a depoimentos da vítima, das testemunhas e dos acusados), e envolvendo simultaneamente a prova em vídeo e as demais provas. Após esse recorte, cada argumentação foi analisada e relacionada com alguma das categorias da linguística textual (conforme a tabela 1). As tabelas seguintes apresentam os quantitativos dos argumentos a partir do grupo de origem (Promotor de Justiça, Defensor Público e Julgadores):

Tabela 2 - Argumentação do Promotor de Justiça:

\begin{tabular}{|c|c|c|c|c|c|}
\hline $\begin{array}{c}\text { Prova interpretada } \\
\text { nos excertos }\end{array}$ & $\begin{array}{c}\text { Operadores } \\
\text { argumentativos }\end{array}$ & $\begin{array}{c}\text { Marcadores } \\
\text { de } \\
\text { pressuposição }\end{array}$ & $\begin{array}{c}\text { Indicadores } \\
\text { modais }\end{array}$ & $\begin{array}{c}\text { Índices de } \\
\text { avaliação }\end{array}$ & $\begin{array}{c}\text { Casos } \\
\text { de } \\
\text { polifonia }\end{array}$ \\
\hline Depoimentos & 19 & 1 & 2 & 18 & 0 \\
\hline Vídeo & 12 & 0 & 4 & 22 & 0 \\
\hline Depoimento/vídeo & 18 & 0 & 1 & 28 & 3 \\
\hline Totais & 49 & 0 & 7 & 68 & 3 \\
\hline
\end{tabular}

A argumentação desenvolvida pelo Promotor de Justiça acerca das provas ocorreu em vinte e três excertos, divididos em: nove sobre depoimentos dos acusados, vítima e testemunhas, sete sobre a prova em vídeo e sete compreendendo tanto os depoimentos quanto a prova em vídeo. A prova em vídeo não configurou como elemento preponderante a partir da análise dos dados: a distribuição relativamente uniforme de recursos argumentativos entre os tipos de prova indica a inexistência de distinção quantitativa.

A análise de catorze excertos sobre a prova em vídeo ou a prova em vídeo e outras provas simultaneamente apresenta os seguintes resultados: a) dez excertos têm a argumentação considerando a prova como sendo de natureza substantiva; b) dois excertos inicialmente ressaltam a natureza descritiva; e c) dois excertos neutros, pois no primeiro há pedido de perícia de degravação e no segundo há argumentação sobre o ato da filmagem. Assim, observou-se que a natureza substantiva foi a orientação preponderante. $O$ excerto 25 é expressivo nesse sentido:

Assim, para que Vossas Excelências tenham a real noção da gravidade da agressão, sugiro que assistam ao vídeo em plenário e tirem suas conclusões. $\mathbf{O}$ poder persuasivo e de síntese das imagens supera a tudo que possamos escrever aqui.

No excerto analisado, o vídeo não é mera explicação de outra prova (natureza demonstrativa): é possível notar pela argumentação empregada que, para o Promotor de Justiça, as filmagens comprovariam a existência da agressão (argumento pressuposto) e a gravidade da intensidade dessa agressão. Em outro excerto, reafirma com veemência os requisitos de um pedido condenatório a partir do vídeo: (...) "Sustentou o Promotor de Justiça que tanto a autoria quanto a materialidade ficaram comprovadas no filme" (excerto 20). 
Apesar de no direito processual penal brasileiro não estar previsto um procedimento prévio de admissibilidade das provas (tópico 2), o Promotor de Justiça é o responsável por requerer a autenticação da prova. No caso em estudo, o vídeo não foi submetido à análise de um perito para validar sua autenticidade. A autenticação se limitou à confiança depositada no depoimento da quarta testemunha que "confiscou o celular e copiou as cenas da agressão" (excerto 24). Esse procedimento de autenticação é característico de evidências demonstrativas, baseado na cumulatividade com uma evidência substantiva. Logo, há um descompasso entre os critérios de admissão da prova e sua valoração, conforme observado nos estudos de Silbey ${ }^{37}$.

O único requerimento de perícia formulado pelo Promotor de Justiça foi "como medida de economia processual, a transcrição do áudio do filme inserto no CD do Anexo 1" (excerto 11). Com isso, buscou transformar a prova em vídeo em um texto com as palavras ditas, desprezando elementos multimodais importantes, como olhares, gestos, movimentos e entonação, essenciais à apreciação da prova. O laudo pericial resultante desse pedido não foi discutido no processo por nenhum dos envolvidos. $O$ pedido de transcrição indica seu estranhamento em lidar com a prova em vídeo e a necessidade de alfabetização visual.

A última conclusão sobre a argumentação do Promotor de Justiça é a prevalência dos índices de avaliação nos excertos em que a argumentação se baseia na prova em vídeo ou na prova em vídeo e outras provas simultaneamente. Como um recurso essencialmente subjetivo, o seu uso pode ser influenciado tanto pelo inconsciente, quanto por um agir estratégico. A argumentação do Promotor de Justiça ressaltou seu poder acusatório. No excerto 21 afirma que o golpe de jiu-jitsu foi "perigosíssimo" e "extremamente violento". Esse excerto não permite, contudo, verificar uma decisão inconsciente ou consciente na valoração do vídeo por parte do Promotor.

Tabela 3 - Argumentação do Defensor Público:

\begin{tabular}{|c|c|c|c|c|c|}
\hline $\begin{array}{c}\text { Prova interpretada } \\
\text { nos excertos }\end{array}$ & $\begin{array}{c}\text { Operadores } \\
\text { argumentativos }\end{array}$ & $\begin{array}{c}\text { Marcadores de } \\
\text { pressuposição }\end{array}$ & $\begin{array}{c}\text { Indicadores } \\
\text { modais }\end{array}$ & $\begin{array}{c}\text { Índices de } \\
\text { avaliação }\end{array}$ & $\begin{array}{c}\text { Casos de } \\
\text { polifonia }\end{array}$ \\
\hline Depoimentos & 78 & 6 & 20 & 67 & 2 \\
\hline Vídeo & 4 & 0 & 0 & 2 & 1 \\
\hline Depoimentos/vídeo & 4 & 0 & 0 & 6 & 0 \\
\hline Totais & 86 & 6 & 20 & 77 & 4 \\
\hline
\end{tabular}

A argumentação do Defensor Público sobre as provas ocorreu em vinte e um excertos. As menções relativas aos depoimentos de acusados, vítima e testemunhas, em dezessete. Em dois excertos com idêntico teor (28 e 40), há indefinição sobre a preponderância do argumento, se uma menção à prova ou aos depoimentos das testemunhas do processo. O mesmo ocorre no excerto 03, quando afirma que os autores "aplicaram golpes de jiu-jitsu, dentre outras formas de agressão

37 SILBEY, Jessica. University of Michigan Journal of Law Reform, p. 570-571. 
leve". Não é possível saber se o argumento foi repetição do texto da denúncia, dos depoimentos da vítima, das testemunhas ou sua interpretação do conteúdo em vídeo. Com isso, não se sabe se a defesa argumentou diretamente sobre o vídeo. Em outros excertos, 32 e 44, apenas mencionou que a permissão dos acusados ao ato de filmar comprovaria suas intenções voltadas a uma brincadeira. Assim, observou-se a preponderância no uso de operadores para o deslocamento da força argumentativa para alegações sobre: 1 - a ausência de dolo de praticar um ato de violência, 2 - a caracterização da ação como "brincadeira", 3 - a existência de costume envolvendo as "brincadeiras" naquela unidade militar, e 4 - a participação da vítima em atos dessa natureza, inclusive envolvendo os acusados. A transcrição do excerto 32 demonstra a estratégia argumentativa da defesa:

A ideia de que não se tratava de um ilícito, e sim, uma "brincadeira", era tão sólida que os acusados, inclusive, deixaram que um terceiro soldado filmasse o ocorrido. É óbvio que se tivessem uma potencialidade criminosa em suas condutas não teriam permitido que se produzisse tal prova.

Logo, é possível inferir que o Defensor Público interpretou o vídeo como prova substantiva ao reconhecer sua potencialidade de provar o fato registrado segundo o seu ponto de vista (da "brincadeira"). Contudo, a defesa não explorou a potencialidade de seu conteúdo: não demonstrou o caráter controverso de diversos elementos multimodais presentes na mídia, como a movimentação dos participantes, sons, o foco e a ausência de registro do início do ato. Restringiu sua interpretação à caracterização do fato como mera "brincadeira". Logo, não houve refutação mais contundente aos argumentos construídos pelo Promotor de Justiça.

O Defensor Público não questionou, igualmente, a autenticidade da filmagem, o modo de sua obtenção pela quarta testemunha ${ }^{38}$, a cadeia de custódia e a identidade dos participantes em sua sustentação oral em plenário, elementos não questionáveis em uma evidência demonstrativa.

Tabela 4 - Argumentação dos Julgadores:

\begin{tabular}{|c|c|c|c|c|c|}
\hline $\begin{array}{c}\text { Prova interpretada } \\
\text { nos excertos }\end{array}$ & $\begin{array}{c}\text { Operadores } \\
\text { argumentativos }\end{array}$ & $\begin{array}{c}\text { Marcadores de } \\
\text { pressuposição }\end{array}$ & $\begin{array}{c}\text { Indicadores } \\
\text { modais }\end{array}$ & $\begin{array}{c}\text { Índices de } \\
\text { avaliação }\end{array}$ & $\begin{array}{c}\text { Casos de } \\
\text { polifonia }\end{array}$ \\
\hline Depoimentos & 4 & 0 & 1 & 3 & 0 \\
\hline Vídeo & 10 & 0 & 4 & 13 & 2 \\
\hline Depoimentos/vídeo & 10 & 0 & 3 & 11 & 0 \\
\hline Totais & 24 & 0 & 8 & 27 & 2 \\
\hline
\end{tabular}

A preferência dos Julgadores recaiu pela argumentação centrada na prova em vídeo e na prova em vídeo em conjunto com depoimentos, como se pode constatar pelo quantitativo de excertos presentes na tabela (sete dos nove apurados). Os índices de avaliação apresentaram a maior incidência dentre os recursos argumentativos, indicando intensa atividade interpretativa, sobretudo quanto ao vídeo.

38 Não houve debate sobre a licitude ou não do ato de confisco do celular para copiar o arquivo de mídia. 
Os Julgadores consideraram o registro audiovisual como sendo uma prova de natureza substantiva. No excerto 50, a Juíza-Auditora se refere aos pedidos insistentes da vítima para que o ato cessasse, informação obtida diretamente das filmagens, pois em nenhum dos depoimentos colhidos mencionou-se esse dado. No excerto 53, o Ministro Relator torna evidente a adoção dessa caracterização ao afirmar:

Não há que se falar em ausência de dolo específico, pois ainda que se tenha alegado que o fato não passou de uma "brincadeira", ainda assim, não há como ignorar que o Apelante agiu livre e conscientemente no sentido de subjugar a vítima com um golpe de jiu-jitsu que poderia lesioná-la gravemente.

Em razão da percepção da prova em vídeo como elemento substantivo, qualquer dos julgadores poderia ter questionado sua licitude (obtida mediante o confisco do telefone celular realizado pela $4^{a}$ testemunha, ato praticado sem autorização legal ou judicial).

Dentre as provas produzidas, o vídeo foi a mais relevante. Para a Juíza-Auditora, através dele se comprovaram a materialidade delitiva e a autoria das condutas. Conforme o excerto 49, "o emprego da força física resta bastante claro pelas imagens" ("bastante claro" atuou como outro índice de avaliação com alta carga argumentativa, sobre o elemento materialidade delitiva), que indicaram a autoria "robustamente" (outro índice de avaliação com elevada carga argumentativa). O Ministro Relator também utilizou o vídeo para firmar os entendimentos de que o $1^{\circ}$ acusado foi o autor da conduta e que o ato reputado como violento realmente ocorreu (excerto 53). A valoração dessa prova com tamanha relevância reforça os comentários do parágrafo anterior sobre a necessidade de maior atenção à autenticação da evidência, como alertado por Silbey ${ }^{39}$.

No excerto 54, a argumentação do Ministro Relator demonstra influência da teoria da testemunha silenciosa ao revelar, após assistir ao vídeo, a potencialidade lesiva do golpe praticado:

E ressalto, ao assistir o vídeo acostado nos autos (Anexo 1), posso assegurar que a gravidade do golpe aplicado à vítima poderia ter-lhe causado danos, quiçá irreversíveis.

Esse mesmo tipo de golpe, inclusive, lesionou um conhecido lutador brasileiro em evento do UFC (Ultimate Fighting Championship).

O emprego do modalizador epistêmico "posso assegurar", na primeira parte desse excerto, revela grau de certeza típico de uma testemunha ocular.

A análise também revelou a influência de sentimentos do Ministro acerca de conhecimentos prévios. No excerto 52, ao afirmar que "o golpe aplicado, o arm-lock, é potencialmente lesivo, e a possibilidade de ocorrência de um resultado mais grave, como uma lesão corporal, era concreta", o

39 SILBEY, Jessica. Race, Religion, Gender \& Class, p. 107. 
magistrado demonstrou conhecimento a respeito da natureza do golpe. Essa observação é reforçada pela segunda parte do excerto 54: "esse mesmo tipo de golpe, inclusive, lesionou um conhecido lutador brasileiro em evento do UFC". Tais trechos ativados de suas memórias poderiam estar associados a vieses inconscientes ${ }^{40}$, como quando realizou a associação mental entre o ato praticado pelos acusados e o evento denominado UFC (Ultimate Fighting Championship), no qual um lutador é colocado em um ringue em formato de jaula para tentar subjugar seu oponente com violentos golpes de artes marciais. Dentre os recursos disponíveis, existe o arm lock, destinado a fraturar os ossos de membro superior do adversário. Essa referência a uma memória prévia reforça a necessidade do treinamento visual dos julgadores para evitar os preconceitos registrados em seus subconscientes ${ }^{41}$.

Após a elaboração das tabelas 2, 3 e 4 tornou-se possível a triangulação dessas fontes de informação sobre a forma de argumentar, obtendo-se a última tabela:

Tabela 5 - Compilação dos dados referentes a todos os argumentos empregados no caso:

\begin{tabular}{|c|c|c|c|c|c|}
\hline $\begin{array}{c}\text { Prova interpretada } \\
\text { nos excertos }\end{array}$ & $\begin{array}{c}\text { Operadores } \\
\text { argumentativos }\end{array}$ & $\begin{array}{c}\text { Marcadores de } \\
\text { pressuposição }\end{array}$ & $\begin{array}{c}\text { Indicadores } \\
\text { modais }\end{array}$ & $\begin{array}{c}\text { Casos de } \\
\text { polifonia }\end{array}$ & $\begin{array}{c}\text { Índices } \\
\text { de } \\
\text { avaliação }\end{array}$ \\
\hline Depoimentos & 102 & 7 & 23 & 2 & 87 \\
\hline Vídeo & 26 & 0 & 8 & 4 & 39 \\
\hline Depoimentos/vídeo & 32 & 0 & 4 & 3 & 45 \\
\hline Totais & 160 & 7 & 35 & 9 & 171 \\
\hline
\end{tabular}

Consoante a tabela 5, os recursos argumentativos mais empregados foram os operadores argumentativos e os índices de avaliação. O Promotor de Justiça preferiu recorrer aos índices de avaliação (68 ocorrências, conforme a tabela 2), demonstrando intensa atividade interpretativa do vídeo baseada em aspectos subjetivos. O Defensor Público adotou com maior recorrência os operadores argumentativos (86 ocorrências, conforme a tabela 3), permitindo o direcionamento da força argumentativa para enfatizar determinados aspectos dos depoimentos das testemunhas em detrimento de outros aspectos. Os Julgadores utilizaram ambos os recursos em quantidade quase idêntica (24 operadores argumentativos e 27 índices de avaliação, conforme a tabela 4).

\section{CONSIDERAÇÕES FINAIS}

A pesquisa, de orientação empírica, qualitativa e descritiva, adotou o método do estudo de caso para analisar o modo como os profissionais do direito construíram seus argumentos em torno da imagem em um processo conduzido na Justiça Militar da União. A hipótese era a de que a argumentação desenvolvida não seria satisfatória dadas as peculiaridades da prova em registro audiovisual e a ausência de um tratamento específico no Brasil para essa espécie de prova. Após

40 SHERWIN, Richard K. Visualizing law in the age of the digital baroque: arabesques and entanglements, $p$. 43.

41 KAHAN, Dan M. Whose eyes are you going to believe? Scott v. Harris and the perils of cognitive illiberalism, p. 895-897. 
a exposição de estudos acerca da problemática envolvendo a interpretação da prova em vídeo no campo do direito (tópico 2), a demonstração da relevância da interface entre o direito e a linguística textual para a avaliação de aspectos sobre as argumentações travadas (tópico 3) e a delimitação da metodologia empregada (tópico 4), os dados coletados foram analisados (tópico 5).

A partir do caso estudado, verificou-se o modo como os profissionais do direito envolvidos no processo perceberam o caráter da prova, substantiva ou demonstrativa, e construíram os argumentos em torno do vídeo utilizado como fundamento do processo. $\mathrm{E}$, a pesquisa analisou a capacidade dos profissionais do direito em interpretar as imagens contidas no vídeo.

Analisando a preferência sobre o tipo de prova, observou-se que ao Promotor de Justiça preponderaram as alegações baseadas na prova em vídeo ou na prova em vídeo acompanhada da prova oral, perfazendo catorze excertos dos vinte e três verificados (conforme a tabela 2). Os Julgadores igualmente preferiram esses tipos de sustentações para seus argumentos, presentes em sete dos nove excertos observados (conforme a tabela 4). A argumentação do Defensor Público preponderou sobre os depoimentos dos acusados, vítima e testemunhas, correspondendo a dezessete de um total de vinte e um excertos (vide tabela 3).

A prova em vídeo foi considerada como de natureza substantiva pela unanimidade dos argumentadores. Todos a utilizaram para tentar provar as teses defendidas. Para o Promotor de Justiça e Julgadores, o vídeo comprovava a autoria dos acusados e a materialidade delitiva, conduzindo à condenação. O Defensor Público, por seu turno, utilizou o ato de filmar (e não o conteúdo do vídeo propriamente dito) para sustentar a versão de o ato praticado ser uma mera brincadeira. Embora todos tenham reconhecido essa natureza substantiva da prova, nenhum deles preocupou-se com os aspectos referentes a sua legitimidade. A ausência de autenticação satisfatória, já que a única forma de autenticação ocorreu por meio do depoimento da $4^{a}$ testemunha, a responsável pelo "confisco" do telefone celular e extração do vídeo para posterior inserção no inquérito policial militar, é expediente próprio de evidências demonstrativas, estando em descompasso com a natureza com que a prova em vídeo foi valorada.

Além disso, o Promotor de Justiça e os Julgadores a compreenderam como a mais relevante para a atividade de persuasão e para firmar as decisões condenatórias. No excerto 25, o Promotor de Justiça revelou essa predileção com tamanha ênfase quando declarou ser o poder de convencimento dela maior que o de qualquer argumento por ele apresentado (esse comentário, aliás, indica que a interpretação dele se assemelhou ao conteúdo da teoria da testemunha silenciosa). Observando-se o mesmo com relação ao Ministro Relator, o qual afirmou serem as filmagens tão reais a ponto de Ihe permitir a sensação de estar testemunhando o evento do filme. No excerto 54, chegou a garantir ser verdadeiro o declarado sobre a potencialidade do golpe aplicado ao empregar o modalizador epistêmico "posso assegurar". 
A ausência de argumentos do Defensor Público sobre o conteúdo da prova em registro audiovisual pode ter representado parte de sua estratégia ou reflexo de ter sentido "o vídeo falando por si". Esta última possibilidade resultaria da interpretação das imagens como sendo tão desfavoráveis aos acusados que preferiu nada dizer sobre elas, buscando conferir maior destaque a outros elementos de prova presentes. Em qualquer dos casos, verifica-se a deficiência de recursos em sua caixa de ferramentas para interpretar o vídeo: poderia argumentar sobre a falta de legitimidade na coleta do vídeo, ausência de comprovação de cadeia de custódia idônea, os possíveis vieses existentes nas imagens e nos áudios, calcados nas diferentes entonações, nos risos, no estreito foco da câmera, dentre outras possibilidades. O Promotor de Justiça também revelou estar despreparado para lidar com essa prova audiovisual ao requerer a transcrição do seu áudio, desprezando outros elementos multimodais além das palavras contidas nas falas. A transcrição, embora tenha sido anexada aos autos, em nenhum momento foi utilizada nas argumentações, revelando-se providência inócua.

A análise dos excertos revelou, ainda, a ativação de memórias do Promotor de Justiça e dos Julgadores na tentativa de conferir sentido às imagens assistidas. Relacionaram as ações na prova em vídeo ao campeonato de artes marciais mistas UFC, gerando a conclusão da natureza violenta do ato praticado pelo $1^{\circ}$ acusado. Outras relações igualmente seriam possíveis, como a eventos de treinamento e a simulações de combate, não orientados ao dolo da prática de violência. Entretanto, esses vieses não foram explorados por nenhum dos profissionais atuantes no feito.

Em síntese, puderam ser obtidas as seguintes inferências da análise dos dados: a) reconhecimento por partes de todos os profissionais como a prova em vídeo sendo a mais relevante para o deslinde do feito; b) elevado uso de índices de avaliação para o direcionamento da força argumentativa do Promotor de Justiça e dos Julgadores para enfatizar o conteúdo da prova em vídeo; c) elevado uso de operadores argumentativos pelo Defensor Público de modo a direcionar a força de sua argumentação a aspectos dos depoimentos das partes para tentar neutralizar o impacto das imagens do vídeo; d) os profissionais omitiram-se à análise da legitimidade da prova, aceitando sua autenticação por mero relato de testemunha, expediente sequer aceito em documentos escritos (a autenticidade documental se comprova por exame documentoscópico); e) o Promotor de Justiça e o Defensor Público deixaram de explorar as potencialidades dos elementos multimodais do vídeo na persuasão racional dos Julgadores; f) os Julgadores e o Promotor de Justiça não souberam identificar os vieses inconscientes influenciadores de seus juízos de valor, incidindo na teoria da testemunha silenciosa; e g) todos "deixaram o vídeo falar por si", ignorando a subjetividade do conteúdo da filmagem. Essas inferências comprovaram a hipótese inicialmente posta, restando patente a deficiência da argumentação empregada acerca da prova em vídeo. Embora haja críticas sobre a potencialidade do método do estudo de caso para a construção de conclusões generalizantes, a confirmação da hipótese indica a necessidade de uma maior alfabetização visual por parte dos profissionais em direito atuando no Brasil. A imagem ainda é um campo desconhecido e há dificuldade para compreender suas especificidades. 
São recomendadas novas pesquisas sobre o tema, em especial a realização de estudo de casos múltiplos, permitindo a triangulação de mais fontes para o estabelecimento de conclusões generalizantes ainda mais seguras, e a elaboração de um modelo para a interpretação do conteúdo audiovisual. Essas novas pesquisas, incorporando o problema da cultura jurídica, da alfabetização visual e do uso dos distintos modos argumentativos é central para o desenvolvimento do campo e da prática judicial em torno dessa desafiadora espécie de prova.

\section{REFERÊNCIAS DAS FONTES CITADAS}

ASIMOW, Michael. Lawyers in your Living Room: law on television. Chicago: American Bar Association, 2009.

BRASIL. Superior Tribunal Militar. Apelação $n^{\circ}$ 0000031-58.2010.7.04.0004. Apelante: A.L.E. Apelado: Ministério Público Militar. Relator: Ministro Cleonilson Nicácio da Silva. Brasília, 11 de setembro de 2012.

BROWN, Michele. Visual Criminology. Oxford Research Encyclopedia of Criminology, Oxford: Oxford University Press, 2017, p. 1-33.

CARRABINE, Eammon., Just images: aesthetics, ethics and visual criminology. British Journal of Criminology, Oxford, v. 52, Issue 3, May 2012, p. 463-489

DENZIN, Norman K. \& LINCOLN, Yvonna. Collecting and Interpreting Qualitative Materials. London: Sage, 1998.

ESTADOS UNIDOS DA AMÉRICA. Suprema Corte. 550 U.S. 372. Scott v Harris. Relator Juiz Antonin Gregory Scalia. Washington, 30 de abril de 2007.

FELICE, Deborah. II Sapere Specialistico nel Giudizio Penale: profili d'analisi di sociologia del diritto. Milano: Mimesis, 2014.

, Deborah, SAGRI, Teresa, BACCI, Lorenzo, AGNOLONI, Tommaso. I "Nuovi" strumenti di conoscenza nella costruzione del giudizio penale: un'analisi tra sociologia del diritto e informatica giuridica. In: GHEZZI, Morris; MOSCONI, Giuseppe; PENNISI,Carlo; PRINA; RAITERI, Monica (coor.). Processo Penale, Cultura Giuridica e Ricerca Empirica, Santarcangelo di Romagna: Maggioli, 2017, p. 55-88.

GARAPON, Antoine. Bien Juger: Essai Sur le Rituel Judiciaire. Paris: Odile Jacob, 1997, p. 270

GARDNER, Dillard S. The Camera goes to court. North Carolina Law Review, Chapel Hill, v. 24, n. 3,, pp. 233 - 246, 1946.

GIL, Antonio C. Como elaborar projetos de pesquisa. 4 ed. São Paulo: Atlas, 2002.

GROARKE, Leo, PALCZEWISKI, Catherine H.; GODDEN, David. Navigating the visual turn in argument. Argumentation and Advocacy, Milton Park, v. 52, pp. 217-235, 2016.

GUNTHER, Hartmut. Pesquisa Qualitativa Versus Pesquisa Quantitativa: Está É a Questão? in Psicologia: Teoria e Pesquisa, v. 22, n. 2. Brasília: Universidade de Brasília, mai/ago de 2006. Disponível em: <http:// dx.doi.org/10.1590/S0102-37722006000200010>. Acesso em 25/09/2017.

KAHAN, Dan M. Whose eyes are you going to believe? Scott v. Harris and the perils of cognitive illiberalism. Harvard Law Review, Harvard, vol. 122, n. 3,pp. 837-906, 2009.

KJELDSEN, Jens. The study of visual and multimodal argumentation. Argumentation, Berlim, v. 29, pp. $115-132,2015$. 
$\mathrm{KOCH}$, Ingedore Grunfeld Villaça. A intertextualidade como critério de textualidade. Cadernos PUC (São Paulo), São Paulo, v. 22, n.4, pp. 39-46, 1986.

Argumentação e Linguagem. 13 ed. São Paulo: Cortez, 2011.

A inter-ação pela linguagem. 11 ed. São Paulo: Contexto, 2015.

Introdução à linguística textual: trajetória e grandes temas. 2 ed. São Paulo: Contexto, 2017.

KOT, Alex; CAO, Hong. Digital Image Forensics: There is More to a Picture than Meets the Eye. Berlim: Springer, 2013.

LEVY, Pierre. Cibercultura. Tradução Carlos Irineu da Costa. São Paulo: Editora 34, 1999.

LIMA, Renato Brasileiro de. Manual de processo penal. v.1. Niterói: Impetus, 2011.

LODER, Letícia Ludwig. O modelo Jefferson de transcrição: convenções e debates. In: LODER, Letícia L; JUNG, Neiva Maria. (coords). Fala-em-interação social: introdução à análise da conversa etnometodológica. Campinas: Mercado das Letras, 2008, p. 127-161.

LOPES JÚNIOR, Aury. Direito processual penal e sua conformidade constitucional, v. 1. 5 ed. Rio de Janeiro: Lumen Juris, 2011.

MADEIRA, Denis Cruz. Argumentação jurídica. Curitiba: Juruá, 2014.

MINAS GERAIS. Auditoria da $4^{a}$ Circunscrição Judiciária Militar. Ação Penal Militar $\mathbf{n}^{\circ} 0000031$ 58.2010.7.04.0004. Autor: Ministério Público Militar. Acusados: A.L.E. e M.V.B. Juiz de Fora, 25 de março de 2010.

PHILIPPI JR., Arlindo; SILVA NETO, Antônio J. (coors.). Interdisciplinaridade em ciência, tecnologia \& inovação. São Paulo: Manole, 2011.

RICCIO, Vicente, VIEIRA, Amitza Torres, GUEDES, Clarissa Diniz. Video evidence, legal culture and court decision in Brazil. In: Frameworks for Discursive Actions and Practices of the Law, TESSUTO, Girolamo; BHATIA, Vijay K.; ENGBERG, Jan (coor). Cambridge: Cambridge Scholars Publishing, 2018, pp. 333-347.

ROQUE, Georges. Esquisse d'une rhétorique des interactions verbo-iconiques. Images Re-vues, Paris, v.5, 2016, pp. 1-19.

SHERWIN, Richard K. Visualizing law in the age of the digital baroque: arabesques and entanglements. New York: Routledge, 2011.

SILBEY, Jessica. Judge as film critics: new approaches to filmic evidence. University of Michigan Journal of Law Reform, Ann Arbor, vol. 37, n. 2.pp. 493-571, 2004.

Cross-examining film. Race, Religion, Gender \& Class, Baltimore, v. 8, n. 17. pp. 17-46, 2008.

TAIT, David. Rethinking the role of the image in justice: visual evidence and science in the trial process. Law, Probability and Risk, 6, 2007, pp. 311-318.

THOMPSON, John. A Mídia e a Modernidade. Petrópolis: Vozes, 1998.

THOMPSON, Geoff; HUNSTON, Susan. Evaluation in Text: Authorial Stance and the Construction of Discourse. Oxford: Oxford University Press, 2000.

YIN, Robert K. Estudo de caso: planejamento e métodos. 5 ed. Porto Alegre: Bookman, 2015.

Pesquisa qualitativa do início ao fim. Porto Alegre: Penso, 2016. 
YOWELL, Amelia G. Race to judgment? An empirical study of Scott v. Harris and summary judgment. Notre Dame Law Review, Notre Dame, v. 85, n 4, 2010, pp. 1759-1786.

Recebido em: $14 / 05 / 2020$

Aprovado em: 21/12/2020 